BMJ Open

Sport \&

Exercise

Medicine

\title{
Sports injuries and illnesses in first-year physical education teacher education students
}

\author{
Anne-Marie van Beijsterveldt, ${ }^{1}$ Angelo Richardson, ${ }^{1}$ Benjamin Clarsen, ${ }^{2}$ \\ Janine Stubbe ${ }^{1,3}$
}

To cite: van Beijsterveldt A$M$, Richardson A, Clarsen B, et al. Sports injuries and illnesses in first-year physical education teacher education students. BMJ Open Sport Exerc Med 2017;3: 0000189. doi:10.1136/bmjsem-2016000189

Accepted 13 December 2016

CrossMark

\section{${ }^{1}$ Faculty of Sports and Nutrition, Amsterdam University of Applied Sciences, Amsterdam, the Netherlands \\ ${ }^{2}$ Norwegian School of Sports Sciences, Oslo Sports Trauma Research Center, Oslo, Norway ${ }^{3}$ Codarts, University of the Arts, Rotterdam, the Netherlands}

Correspondence to Anne-Marie van Beijsterveldt; a.m.c.van.beijsterveldt@hva. $\mathrm{nl}$

\section{ABSTRACT}

Background/aim We aimed to investigate the magnitude and characteristics of injuries and illnesses in Dutch physical education teacher education (PETE) students.

Methods During the first 21 weeks of the academic year, 245 first-year students registered their health problems online using the Oslo Sports Trauma Research Centre (OSTRC) Questionnaire on Health Problems.

Results A total of 276 injuries, 140 illnesses and 69 unclassified health problems were reported. We found an injury incidence rate of 11.7 injuries per 1000 hours $(95 \% \mathrm{Cl} 10.4$ to 13.2$)$. Injury characteristics were: $42 \%$ overuse injuries, $62 \%$ causing absence from sports (median injury time loss $=2$ days) and $64 \%$ reinjuries. Most injuries were located at the knee, lower leg (anterior) and ankle. The duration of the illnesses was short $(<1$ week).

Summary and conclusions We implemented a new registration method in the PETE academic programme. The results show that the risk for health problems is high for PETE students. Prevention is necessary, and to decrease injuries prevention programmes should focus on the lower extremities.

\section{INTRODUCTION}

Physical activity is a key contributor to health. Sports participation is one way of obtaining physical activity. ${ }^{1}$ The downside of participation in sports is the increased risk of sports-related injuries. ${ }^{2}{ }^{3}$ Physical education teacher education (PETE) students participate in a wide range of different sports, which puts them at increased risk for various injuries. ${ }^{4}$ These injuries can carry severe consequences for PETE students, since they can lead to decreased physical performance, absence from sports classes and financial loss caused by higher study career costs or medical treatment. ${ }^{5}$ In addition, after graduation, PETE students will teach physical education in schools and/or will be engaged in sports training. Previous injury is a significant predictor of injury susceptibility, ${ }^{6} 7$ and

\section{What are the new findings?}

- This is the first study using the Oslo Sports Trauma Research Centre (OSTRC) method to the physical education teacher education (PETE) academic programme. The results show that the risk for health problems is high for first-year PETE students.

- A total of 2059 questionnaires were completed during the academic year. Students reported 276 injuries, 140 illnesses and 69 unclassified health problems. We found an injury incidence rate of 11.7 injuries per 1000 hours $(95 \% \mathrm{Cl} 10.4$ to 13.2$)$.

Injury characteristics were: $42 \%$ overuse injuries, $62 \%$ causing absence from sports and $64 \%$ reinjuries. Most injuries were located at the knee, lower leg and ankle.

therefore it is of paramount importance to prevent sports injuries in PETE students during the university programme.

According to the 'sequence of prevention' model by van Mechelen et $a l,{ }^{8}$ in order to develop sports injury prevention programmes in PETE students, we first need to know the characteristics of the problem specifically for our target population. Several studies have described the injury problem in PETE students over the past decades. $^{4} 5^{5} 9-13$ These studies showed that injury incidence in PETE students ranges from 0.9 to 2.1 injuries/student/year. This is a relatively high injury risk compared with the general active population, which has an injury incidence of 0.36 injuries/athlete/year. ${ }^{14}$

One of the drawbacks of the majority of the above-mentioned studies is the use of a time loss definition to define injuries. This definition underestimates the burden of injury because many athletes with overuse injuries continue to participate despite pain and reduced performance. ${ }^{15}{ }^{16}$ When time loss definitions are used, about $90 \%$ of overuse injuries appear to be missed. ${ }^{16}$ 
Recently, a new surveillance method was developed which enables us to record all types of health problems, including overuse injuries, acute injuries and illnesses. ${ }^{17}$ In comparison with standard methods of injury registration, this approach may provide greater information on true consequences of injury over time. ${ }^{16}$ Therefore, the aim of this study was to use this new method and gain more insight into the health issues of PETE students. We focussed on the following research questions: (1) What is the prevalence and incidence of health problems (ie, acute injuries, overuse injuries and illnesses) among Dutch PETE students? (2) What are the characteristics of health problems in PETE students?

\section{METHODS}

All first-year PETE students of the Amsterdam University of Applied Sciences were invited to participate in this prospective cohort study. Their study programme consists, apart from the theoretical courses, of courses in six different sports (gymnastics, field sports, martial arts, dance, athletics and swimming) with a scheduled exposition of 11.5 hours per week. Participants were followed for the first 5 months of their academic year (September 2013-February 2014) and received weekly questionnaires on health problems (described below).

A Dutch version of the Oslo Sports Trauma Research Centre (OSTRC) Questionnaire on Health Problems was sent to all participants using online survey software each Monday during the study period. If no answer was received within 2 days, a reminder email was automatically sent. The questionnaire, which is described in detail elsewhere, consists of four key questions on the consequences of health problems in the previous 7 days, on sports participation, training volume and sports performance as well as the degree of symptoms experienced. ${ }^{17}$ Participants were asked to record the anatomical location of all reported injuries, and the main symptoms experienced for all reported illnesses. They were also asked to record the number of minutes of sport they completed in the previous 7 days, including classes and extracurricular activities. The intake questionnaire which was administrated prior to the start of the study year also included questions on participants' gender, age, history of sports participation and their history of injury and chronic illness.

All baseline characteristics, measured as continuous variables, are presented as mean values with corresponding SD. Ordinal or categorical variables, such as injury history, are presented as percentages. Injury incidence density (ID) was calculated as the number of injuries or illnesses per 1000 sports hours. The corresponding 95\% CIs were obtained using the Poisson model. Other calculations (such as the prevalence and severity score for health problems) were performed using the methodology described by Clarsen et al. ${ }^{16} 17$ The prevalence of substantial problems (ie, a moderate or major reduction in sport activity and/or performance or complete inability to participate) was calculated separately. ${ }^{17}$ To measure the consequences of each reported problem each week, we calculated a severity score ranging from 0 to 100 points, based on the questionnaire's four key questions. ${ }^{16}$

We also addressed some specific issues. First, if a student reported the same type of problem subsequently throughout the data collection period, this was counted as one case of a (fluctuating) problem. Second, to predict data completeness, we analysed the missing responses by assessing baseline differences between compliant (participants who returned $>50 \%$ of all questionnaires) and non-compliant students (who returned $\leq 50 \%$ of all questionnaires), using $\chi^{2}$ analysis. To calculate the relative impact of injuries, an adjusted severity score was calculated for each area by summing athletes' severity scores over the total season, adjusted for group size and response rate. ${ }^{18}$ All statistical procedures were conducted using SPSS 22.

\section{RESULTS}

\section{Baseline characteristics}

In total, 280 first-year students started their education programme at the Amsterdam University of Applied Sciences at the beginning of this study. As 35 students did not fill out the intake questionnaire or any of the weekly questionnaires, the final study population consisted of 245 PETE students. The baseline characteristics were: $29 \%$ women, $71 \%$ men; mean age $19.8 \pm 2.2$ years. Most first-year students reported their own health as being (very) positive $(70.2 \%$ good, $22.7 \%$ excellent). Almost one out of 10 students (9.4\%) had a chronic illness (mainly asthma). The mean sporting time before they started their education was 7.0 hours/ week (SD 3.9). The most popular sports were fitness (34.8\%), soccer $(29.8 \%)$, running $(16.9 \%)$ and tennis (12.6\%). Thirty per cent of students reported an injury lasting at least 1 week in the year before the study started. The most commonly reported injury locations were ankle $(9.5 \%)$ and knee $(7.9 \%)$.

\section{Response and prevalence of health problems}

A total of 2059 questionnaires were completed during the academic year (mean per student $=8$, median $=6$, range 1-21). On average, the weekly response rate to the online survey was $40 \%$. Only 12 students $(4.9 \%)$ completed all questionnaires. During the 21-week follow-up period, the response rate decreased from $79 \%$ to $16 \%$. In 626 of the $2059(30.4 \%)$ questionnaires, a health problem was reported by 184 students. Of these, 417 were caused by an injury (66.6\%), 140 by an illness (22.4\%) and 69 were unclassified (11.0\%). Of all reported health problems, a total of $195(31.2 \%)$ were classified as substantial. A majority of the substantial health problems were injuries $(\mathrm{n}=159,81.5 \%)$. Table 1 shows the average prevalence of health problems. 
Table 1 The average weekly prevalence of all health problems and of substantial problems

Overall \% (95\% Cl)

\begin{tabular}{|l|l|}
\hline All health problems & $30.4(28.1$ to 32.9$)$ \\
\hline Injury & $20.3(18.4$ to 22.3$)$ \\
\hline Acute & $11.7(10.3$ to 13.3$)$ \\
\hline Overuse & $8.5(7.4$ to 9.9$)$ \\
\hline Illness & $6.8(5.8$ to 8.0$)$ \\
\hline Unclassified & $3.4(2.6$ to 4.2$)$ \\
\hline Substantial health problems & $9.5(8.2$ to 10.9$)$ \\
\hline Injury & $7.7(6.6$ to 9.0$)$ \\
\hline Acute & $5.4(4.5$ to 6.5$)$ \\
\hline Overuse & $2.3(1.8$ to 3.1$)$ \\
\hline Illness & $1.2(0.8$ to 1.7$)$ \\
\hline Unclassified & $0.5(0.3$ to 1.0$)$ \\
\hline
\end{tabular}

As shown in figure 1, the prevalence of both substantial and non-substantial injuries increased just before the winter break (week 51).

\section{Characteristics of health problems}

Of all 626 reported health problems, 485 were unique (eg, not mentioned in the previous questionnaire). Of these, 276 were classified as an injury (56.9\%), 140 as illness $(28.9 \%)$ and 69 were unclassified health problems $(14.2 \%)$.

The 140 registered illnesses comprised 532 symptoms (mean 4; range 1-14). Blocked nose/running nose/sneezing (16.2\%), cough $(13.2 \%)$ and sore throat $(10.0 \%)$ were the most prevalent symptoms. The duration of the illnesses was short, since all illnesses were registered only once.

Sixty per cent of all health problems were injuries $(n=276)$. Of these, $115(42 \%)$ were indicated as overuse injuries and $161(58 \%)$ as acute injuries (problems with a sudden onset). More than six out of 10 injuries $(62.3 \%)$ caused absence from sports. This injury time loss ranged from 1 to 50 days, with a median of 2 days. Almost two-thirds of the injuries $(64 \%)$ were reinjuries and the majority occurred during training $(72 \%)$. The knee $(18.5 \%)$, lower leg (anterior) and ankle (both 12.3) were the most injured body parts. The most commonly mentioned diagnoses were strains (15\%), muscle soreness $(8 \%)$ and sprains $(7 \%)$. It appeared difficult for students to diagnose their problem, since in one-third of all reports the diagnosis 'other' was chosen. Table 2 shows a list of commonly injured body locations.

A total of 23538 hours of sporting time were reported during the study. A majority of this time (14 128 hours) was spent at university (classes). The average weekly sporting time was 11.4 hours (SD 6.2), and 6.9 hours per week (SD 4.4) were spent at university. The total sporting time equates to an injury ID of 11.7 injuries per 1000 hours $(95 \% \mathrm{CI}=10.4$ to 13.2$)$ (table 3$)$.

\section{Additional analyses}

Figure 2 shows the top 10 of the relative impact of injuries in each anatomical area, based on the adjusted cumulative severity score over the total study period. As shown in the figure, knee, lower leg and shoulder injuries had the greatest impact.

The missing response analysis showed that women were more compliant to complete the questionnaires than men (39 vs $25 \%$ compliance $/ \mathrm{p}=0.02)$. Also, students with a chronic illness (50 vs $27 \% / \mathrm{p}=0.02$ ) and those reporting no injuries during the study (37 vs $18 \% / \mathrm{p}=0.001)$ were more compliant. No differences were found between students with and without injury history (27 vs $35 \% / \mathrm{p}=0.2$ ).

\section{DISCUSSION}

The main finding of this study was that a total of 276 injuries, 140 illnesses and 69 unclassified health problems were reported. We found an injury incidence rate of 11.7 injuries per 1000 hours (95\% CI 10.4 to 13.2).

\section{How our data compare with previous studies}

Several epidemiological studies on sport injuries in PETE students have been executed over the last
Figure 1 Weekly prevalence of injuries during the 21-week followup period. Full line represents all reported injuries and dotted lines represent substantial injuries.

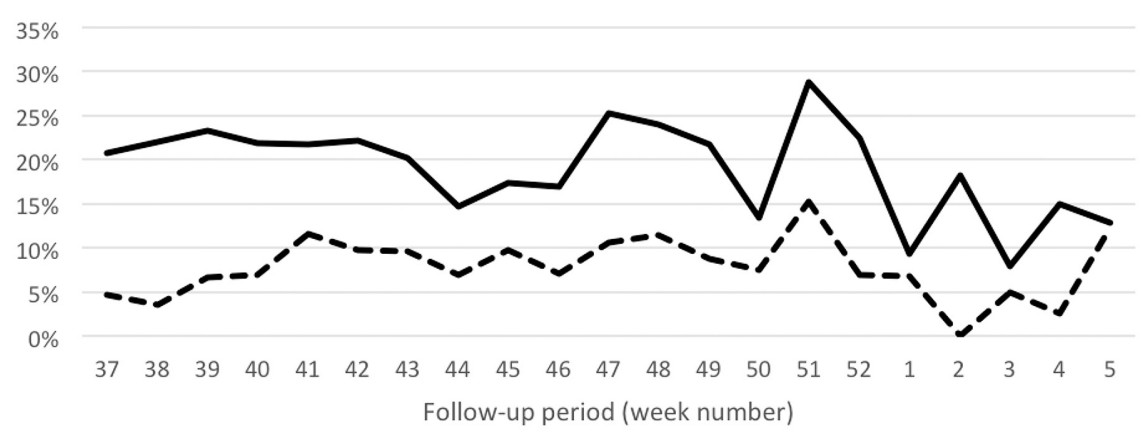

All injuries $\quad$ - - Substantial injuries 
Table 2 Injury locations

Overall number (\%)

\begin{tabular}{|cc|}
\hline All head/neck injuries & $11(3)$ \\
\hline Head & $5(2)$ \\
\hline Neck & $6(2)$ \\
\hline All upper extremity injuries & $49(18)$ \\
\hline Shoulder & $29(11)$ \\
\hline Elbow & $1(0)$ \\
\hline Forearm & $3(1)$ \\
\hline Wrist & $4(1)$ \\
\hline Hand/fingers & $12(4)$ \\
\hline All trunk injuries & $34(12)$ \\
\hline Chest & $4(1)$ \\
\hline Thoracic spine & $7(3)$ \\
\hline Lumbar spine & $22(8)$ \\
\hline Trunk and abdomen & $1(1)$ \\
\hline All lower extremity injuries & $179(65)$ \\
\hline Buttocks & $3(1)$ \\
\hline Hip & $2(1)$ \\
\hline Groin & $18(7)$ \\
\hline Upper leg (anterior) & $6(2)$ \\
\hline Upper leg (posterior) & $4(1)$ \\
\hline Knee & $51(19)$ \\
\hline Lower leg (anterior) & $34(12)$ \\
\hline Lower leg (posterior) & $6(2)$ \\
\hline Achilles tendon & $3(1)$ \\
\hline Ankle & $34(12)$ \\
\hline Foot/toe & $21(8)$ \\
\hline Total & $276(100)$ \\
\hline & \\
\hline
\end{tabular}

decades. The incidence of sports injuries in this research group reported in the literature ranges from 0.9 to 2.1 injuries/student/year. Reported incidence rates vary from 1.4 to 4.0 injuries/ 1000 hours, when taking all sports participation into account..$^{5-}$ 12 19-24 Since most of the studies are outdated, our results are compared with two recent studies. ${ }^{521}$ The injury incidence in our study is much higher than reported in those studies. We found an incidence of 11.7 injuries/1000 exposure hours, whereas Mukherjee and Goossens and coauthors reported incidences of 2.83 injuries/1000 hours and 1.91 injuries/1000 hours, respectively. ${ }^{5} 21$

We believe these differences in injury incidence can be explained by the use of different injury registration methodologies, for example, the use of other
Table 3 Injury incidence characteristics

\section{Overall $(95 \% \mathrm{Cl})$}

\begin{tabular}{lc}
\hline All injuries & $11.7(10.4$ to 13.2$)$ \\
Acute & $6.8(5.9$ to 10.0$)$ \\
Overuse & $4.9(4.1$ to 5.9$)$ \\
\hline
\end{tabular}

injury definitions. Standard injury registration underestimates the true burden of injuries due to a reliance on time loss and/or medical attention injury definitions. ${ }^{16}$ The new method of Clarsen et al identified more than 10 times as many cases than the standard method. As expected, since we also collected data about all health problems (regardless of the absence from sports), the injury incidence in our study is higher than reported in similar, previous studies. Injury time loss also differs considerably between the three studies. In our study, $37.7 \%$ of the injuries caused no absence from sports, whereas this percentage was $22.0 \%$ and $87.7 \%$ in the Belgian study and Singaporean study, respectively. Although the injury incidence rate in our population was higher compared with the other two studies, there were no differences in the majority of injury locations, which was in agreement with other studies. In all three compared studies, injuries to the lower extremity occurred most often in PETE students; ankle and knee were most frequently injured. This suggests that injury prevention programmes for this population should focus on these joints, for example, with multifaceted programmes like FIFA $11+$ or No Gain With Pain (especially developed for PETE students). ${ }^{425}$

Our results showed the highest prevalence of injuries at the beginning of the Christmas holiday. It might be that this high prevalence is related to the intracurricular classes and the busy programme just before the break started. Besides that, it is also known that it takes some time to develop an overuse injury. At the start of the academic year, the load will be gradually increased. Load increases can result in various sports injuries, which can take time to manifest. ${ }^{26} 27$

\section{A new injury registration tool}

The most important strength of this study is that we implemented a new, valid and reliable injury registration method in the first year of the PETE programme. This is the first study to apply the OSTRC method to these students. Although this questionnaire is translated in several languages, ${ }^{28} 29$ only one other study project —outside Norwayusing this questionnaire has been published yet. ${ }^{30}$ Nevertheless, a few other studies used the first version of this questionnaire, focusing on specific 
Figure 2 Top 10 of the relative impact of injuries, shown as the adjusted cumulative severity score (arbitrary units) x 1000 .

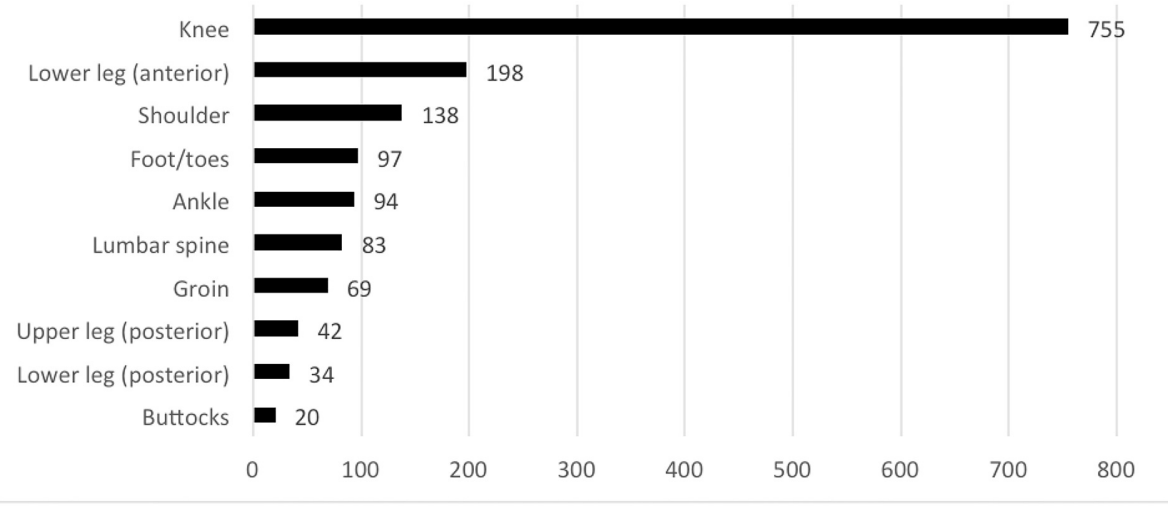

overuse problems in sports. ${ }^{16} \quad 18 \quad 28 \quad 31-33$ Our data collection results in new insights regarding all health problems experienced by these students (eg, about illnesses), since our study did not focus on time-loss injuries only. Our procedure provides knowledge on the load for students during the academic year. This will help the university in future with the next steps of developing a prevention model to prevent injuries in their students and/or to change the intensity of the intracurricular classes.

In this study, we followed the original advice by Clarsen et al to send out the OSTRC questionnaire every week. ${ }^{16}$ Unfortunately, not all students of our research population completed the questionnaires regularly. Possibly the compliance would be higher if students received fewer questionnaires during the study period. In a subsequent article, Clarsen et $a l^{17}$ concluded that it is possible to sample less frequently without influencing primary outcomes (the average prevalence and severity), while the number of identified problems is reduced. However, by sampling less frequently, some shorter duration problems will be missed. Even so, administering this questionnaire biweekly or monthly could be a more practical health monitoring tool. ${ }^{17}$ Less frequent sampling might have boosted compliance, whereas the collected data retain an acceptable level of detail to answer our research questions.

Despite of close follow-up by researchers and the user-friendly possibilities to answer the questionnaire on several devices, it is unknown why the compliance in our study was low. Nevertheless, the missing data analysis seems to indicate that the injury data are valid and shows a reliable reflection of reality. Another limitation is that we used student-reported outcomes. These reports result in general data about health problems, since the students lack medical expertise and their subjective problems were not diagnosed or coded. Since the aim of our study was to investigate the magnitude and characteristics of injuries and illnesses in PETE students, we decided to restrict to this possibly lower data quality. ${ }^{15} \mathrm{We}$ recommend that future studies include a follow-up from the medical staff during the data collection period, to gain more insight into the injury type and aetiology.

Acknowledgement The authors wish to thank Sander Bliekendaal, MSc, for his assistance in collecting the data.

Contributors All four authors have substantially contributed to conception and design, acquisition of data or analysis and interpretation of data; drafting the article or revising it critically for important intellectual content and final approval of the version to be published.

Funding This study was funded by the Taskforce for Applied Research (SIA, reference number 2013-15-12P).

Competing interests None declared.

Ethics approval The study protocol was approved by medical ethics committee of the Amsterdam Academic Medical Centre (AMC) and written consent was obtained from all participants.

Provenance and peer review Not commissioned; externally peer reviewed.

Open Access This is an Open Access article distributed in accordance with the Creative Commons Attribution Non Commercial (CC BY-NC 4.0) license, which permits others to distribute, remix, adapt, build upon this work noncommercially, and license their derivative works on different terms, provided the original work is properly cited and the use is non-commercial. See: http:// creativecommons.org/licenses/by-nc/4.0/

(c) Article author(s) (or their employer(s) unless otherwise stated in the text of the article) 2017. All rights reserved. No commercial use is permitted unless otherwise expressly granted.

\section{REFERENCES}

1. Das $P$, Horton R. Rethinking our approach to physical activity. Lancet 2012;380:189-90.

2. Cumps E, Verhagen E, Meeusen R. Prospective epidemiological study of basketball injuries during one competitive season: ankle sprains and overuse knee injuries. J Sports Sci Med 2007;6:204-11.

3. Frisch A, Seil R, Urhausen A, et al. Analysis of sex-specific injury patterns and risk factors in young high-level athletes. Scand J Med Sci Sports 2009;19:834-41.

4. Goossens L, Cardon G, Witvrouw E, et al. A multifactorial injury prevention intervention reduces injury incidence in Physical Education Teacher Education students. Eur J Sport Sci 2016;16:365-73.

5. Goossens L, Verrelst R, Cardon G, et al. Sports injuries in physical education teacher education students. Scand J Med Sci Sports 2014;24:683-91.

6. Hägglund M, Waldén M, Ekstrand J. Previous injury as a risk factor for injury in elite football: a prospective study over two consecutive seasons. Br J Sports Med 2006;40:767-72.

7. Steffen K, Myklebust G, Andersen TE, et al. Self-reported injury history and lower limb function as risk factors for injuries in female youth soccer. Am J Sports Med 2008;36:700-8. 
8. Van Mechelen W, Hlobil H, Kemper HC. Incidence, severity, aetiology and prevention of sports injuries. A review of concepts. Sports Med 1992;14:82-99.

9. Ehrendorfer S. Survey of sport injuries in physical education students participating in 13 sports. Wien Klin Wochenschr 1998;110:397-400.

10. Fliciński J. [Occurrence and risk factors of musculoskeletal pain and sport injuries in students of physical education in University of Szczecin]. Ann Acad Med Stetin 2008;54:31-47.

11. Lysens RJ, Ostyn MS, Vanden Auweele Y, et al. The accident-prone and overuse-prone profiles of the young athlete. Am J Sports Med 1989;17:612-9.

12. Twellaar M, Verstappen FT, Huson A. Is prevention of sports injuries a realistic goal? A four-year prospective investigation of sports injuries among physical education students. Am J Sports Med 1996;24:528-34.

13. Verstappen FT, Twellaar M, Hartgens F, et al. Physical fitness and sports skills in relation to sports injuries. A four-year prospective investigation of sports injuries among physical education students. Int J Sports Med 1998;19:586-91.

14. Van Mechelen W, Twisk J, Molendijk A, et al. Subject-related risk factors for sports injuries: a 1-yr prospective study in young adults. Med Sci Sports Exerc 1996;28:1171-9.

15. Bahr R. No injuries, but plenty of pain? On the methodology for recording overuse symptoms in sports. $\mathrm{Br} \mathrm{J}$ Sports Med 2009:43:966-72.

16. Clarsen B, Myklebust G, Bahr R. Development and validation of a new method for the registration of overuse injuries in sports injury epidemiology: the Oslo Sports Trauma Research Centre (OSTRC) overuse injury questionnaire. Br J Sports Med 2013;47:495-502.

17. Clarsen B, Rønsen O, Myklebust G, et al. The Oslo Sports Trauma Research Center questionnaire on health problems: a new approach to prospective monitoring of illness and injury in elite athletes. $\mathrm{Br}$ J Sports Med 2014;48:754-60.

18. Clarsen B, Bahr R, Heymans MW, et al. The prevalence and impact of overuse injuries in five norwegian sports: Application of a new surveillance method. Scand J Med Sci Sports 2015;25:323-30.

19. Lysens R, Lefevre J, Renson L, et al. The predictability of sports injuries. A preliminary report. Int J Sports Med 1984;05:S153-S155.

20. Barras L, Sturbois X. Répercussion de la traumatologie Du sport dans les sections d'éducation physique et de kinésithérapie à l'UCL. Louvain Med 1994;113:347-57.
21. Mukherjee S. Sports injuries in university physical education teacher education students: a prospective epidemiological investigation. Int J Sports Med 2014;1:528-35.

22. Conte $M$, Matiello Júnior $E$, Chalita L, et al. Risk factors of sports injuries among university students of physical education in socoroba/SP. Rev Bras Med Esporte 2002;8:151-6.

23. Dane S, Can S, Gürsoy R, et al. Sport injuries: relations to sex, sport, injured body region. Percept Mot Skills 2004;98:519-24.

24. Brennan G, Shafat A, Mac Donncha C, et al. Lower back pain in physically demanding college academic programs: a questionnaire based study. BMC Musculoskelet Disord 2007;8:67.

25. Monajati A, Larumbe-Zabala E, Goss-Sampson M, et al. The effectiveness of injury prevention programs to modify risk factors for non-contact anterior cruciate ligament and hamstring injuries in uninjured team sports athletes: a systematic review. PLoS One 2016;11:e0155272.

26. Gabbett TJ. The training-injury prevention paradox: should athletes be training smarter and harder? Br J Sports Med 2016;50:273-80.

27. Gabbett TJ, Hulin BT, Blanch P, et al. High training workloads alone do not cause sports injuries: how you get there is the real issue. $\mathrm{Br}$ $J$ Sports Med 2016;50:444-5.

28. Ekman E, Frohm A, Ek P, et al. Swedish translation and validation of a web-based questionnaire for registration of overuse problems. Scand J Med Sci Sports 2015;25:104-9.

29. Jorgensen JE, Rathleff CR, Rathleff MS, et al. Danish translation and validation of the Oslo Sports Trauma Research Centre questionnaires on overuse injuries and health problems. Scand $J$ Med Sci Sports 2015;26:1391-7.

30. Pluim BM, Loeffen FG, Clarsen B, et al. A one-season prospective study of injuries and illness in elite junior tennis. Scand J Med Sci Sports 2016;26:564-71.

31. Andersen CA, Clarsen B, Johansen TV, et al. High prevalence of overuse injury among iron-distance triathletes. Br J Sports Med 2013;47:857-61.

32. Clarsen B, Bahr R, Andersson SH, et al. Reduced glenohumeral rotation, external rotation weakness and scapular dyskinesis are risk factors for shoulder injuries among elite male handball players: a prospective cohort study. Br J Sports Med 2014;48:1327-33.

33. Fredriksen $\mathrm{H}$, Clarsen $\mathrm{B}$. High prevalence of injuries in the Norwegian national ballet. Br J Sports Med 2014;48:595.3-6. 